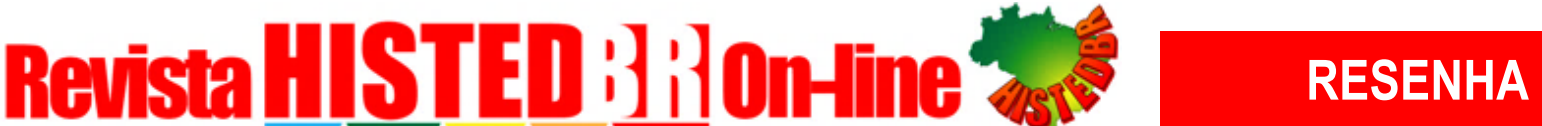

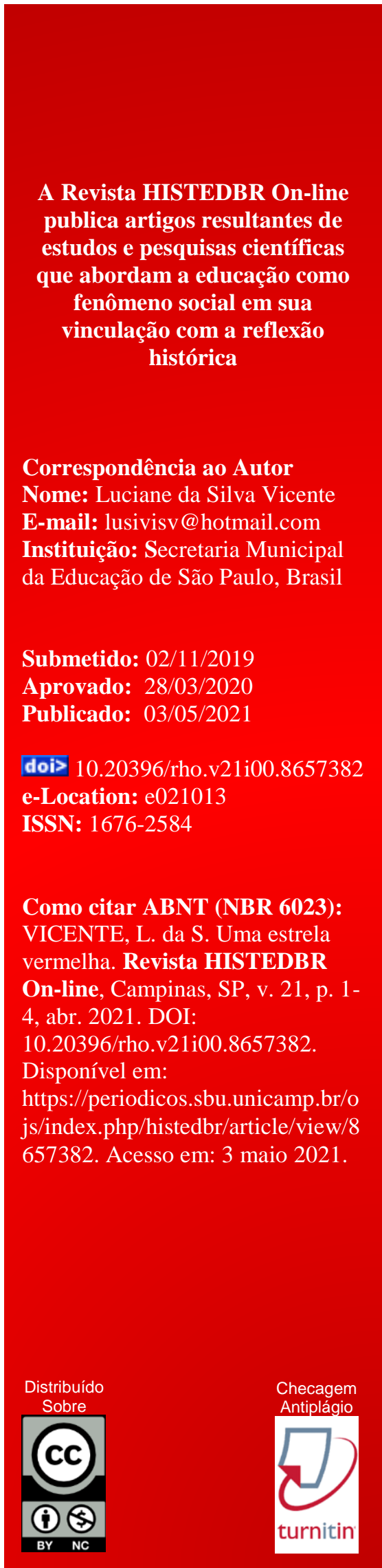

LODI, S. Nadezhda Krupskaia: uma estrela vermelha. Uberlândia: Navegando Publicações, 2018. 115 p.

\section{UMA ESTRELA VERMELHA}

\section{(D. ) Lattes Luciane da Silva Vicente*}

Secretaria Municipal da Educação de São Paulo

fenômeno social em sua histórica

Correspondência ao Autor

Nome: Luciane da Silva Vicente E-mail: lusivisv@hotmail.com

Instituição: Secretaria Municipal da Educação de São Paulo, Brasil

Submetido: 02/11/2019

Aprovado: 28/03/2020

Publicado: 03/05/2021

doi> 10.20396/rho.v21i00.8657382 e-Location: e021013

ISSN: $1676-2584$

Como citar ABNT (NBR 6023):

VICENTE, L. da S. Uma estrela

vermelha. Revista HISTEDBR

On-line, Campinas, SP, v. 21, p. 1-

4, abr. 2021. DOI:

10.20396/rho.v21i00.8657382.

Disponível em:

https://periodicos.sbu.unicamp.br/o js/index.php/histedbr/article/view/8

657382. Acesso em: 3 maio 2021. 


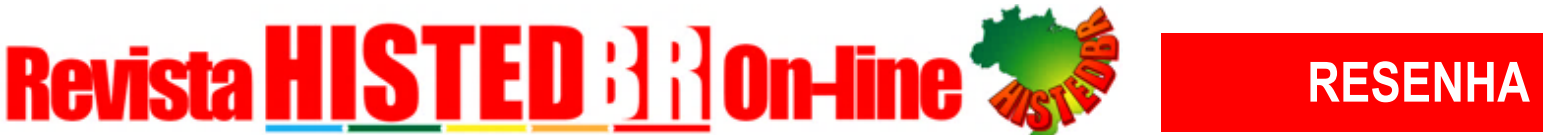

A força de uma mulher que se dedicou a uma vida de militância e viveu anos no exílio por suas publicações que instruíam a classe operária russa a lutar contra a exploração e opressão do capitalismo. A conexão com os trabalhadores, o trabalho em periódicos, o ativismo em prol de uma sociedade coletivista e solidária sob a perspectiva marxista. $\mathrm{O}$ pensamento vinculado aos direitos iguais, para ambos os sexos, independente de classe social em todas as esferas da sociedade. Uma proposta socialista de desenvolvimento integral do ser humano, alicerçada a uma educação emancipatória como elemento chave de transformação do mundo. Esses são alguns temas que Samanta Lodi, ao longo de 115 páginas oferece ao leitor.

Uma estrela vermelha traz um estudo histórico-biográfico de Nadezhda Krupskaia, uma ativista da educação que atuou no processo revolucionário russo ao lado de Lenin. Esta obra é parte da tese da autora, intitulada de Entre a pena e boioneta, defendida em 2016 na Faculdade de Educação da UNICAMP. O livro está dividido em quatro capítulos, precedidos por uma introdução que apresenta os elementos teóricos de análise e os trabalhos publicados no cenário nacional utilizados como aporte de pesquisa.

No primeiro capítulo, intitulado De Tolstoi a Marx, Lodi faz uma breve apresentação de Krupskaia, do seu contexto familiar e das suas primeiras aproximações com a obra de Marx. Conforme Lodi, Krupskaia nasceu em 26 de fevereiro de 1869, em São Petersburgo, era filha de um militar e de uma professora que batalhavam duramente para sobrevivência da família, sendo as dificuldades financeiras, a razão do envolvimento dos seus genitores com as causas sociais. Sobre a conduta do pai, Lodi revela que dela vieram as primeiras sensibilizações de Krupskaia em relação às desigualdades e à necessidade por justiça social que, posteriormente, nela se radicalizam. A leitura mostra que Krupskaia perde seu pai aos quatorze anos e com essa idade inicia seus primeiros trabalhos como professora particular. Posteriormente, abre mão da remuneração diminuta que recebia como professora para trabalhar como voluntária em uma escola para operários. Do contato com os trabalhadores para os quais lecionava, Krupskaia conhece a obra de Marx e o abraça como mentor de suas convicções. Sobre o trabalho com os operários, a autora pontua que, além do aprendizado da leitura e da escrita, a proposta de ensino incluía o desenvolvimento da consciência política de seus alunos. À medida que se envolvia com o pensamento marxista, assumia posicionamentos importantes e incorporava cada vez mais a militância comunista. A parte inicial encerra-se com a exposição do contexto em que Krupskaia conhece Lenin e passam a trabalhar juntos pela divulgação das ideias comunistas.

No segundo capítulo, com o tema $O$ Longo Exílio e as Convicções Comunistas, Lodi relata a perseguição da polícia aos grupos revolucionários liderados por Lenin e Krupskaia, pela distribuição de panfletos considerados ilegais. Essa perseguição, segundo a autora, levou a prisão de Lenin e, posteriormente de Krupskaia, que passou sete meses na prisão, foi julgada e condenada a um exílio de três anos. Fato este, que os levou a contraírem matrimônio e intensificarem as ações do movimento dos trabalhadores. 


\section{Revista HISTED Hiilontine}

RESENHA

No exílio, a autora descreve que Krupskaia lecionava, produzia textos para periódicos e estabelecia contato com os social-democratas que também estavam exilados na localidade. Ainda neste capítulo, Lodi faz uma crítica à forma com que alguns livros atrelam a imagem de Krupskaia à de Lenin. Segundo a autora, Krupskaia é muitas vezes reportada como mulher de Lenin, esposa de Lenin e não como uma revolucionária que atuou durante anos em defesa da classe operária.

Outras duas passagens marcantes que Lodi menciona no segundo capítulo são: 1) a data de nove de janeiro, mais conhecida como Domingo Sangrento, pelo massacre da população que se manifestava pacificamente por estar faminta e cansada da exploração; 2) a rebelião dos marinheiros contra seus oficiais opressores que findou com a jogada destes em alto mar, resultando numa mortandade de pessoas muito maior que o acontecimento de nove de janeiro. É salientada ao leitor a ocorrência de diversas manifestações dos operários, devido à piora das condições de trabalho e às frequentes sentenças de mortes praticadas pelo governo, que se dizia fazer justiça imediata a todos os rebeldes. Nesse momento histórico, Krupskaia e Lenin se locomovem constantemente de um lugar para outro em busca de proteção e se dedicam à produção de textos voltados à construção de uma educação comunista.

Como o intuito de facilitar compreensão do processo revolucionário no qual Krupskaia se inseriu, Lodi inicia o terceiro capítulo, Revolução Russa e Governo Soviético, situando o leitor sobre os acontecimentos que se sucederam na Revolução Russa e, como resultado, no retorno de Krupskaia e Lenin do exílio. Ao retornar à Rússia, a autora descreve que além de redigir diversos artigos voltados para o público jovem encorajando-os a lutar contra a exploração e opressão do capitalismo, Krupskaia encontrava-se pessoalmente com esse público para dar continuidade ao seu trabalho de propagação do comunismo. Também é relatada a ocorrência de diversos movimentos tendo mulheres à frente na luta por igualdade.

Outro ponto mencionado que merece a atenção do leitor foi a importante atuação de Krupskaia, junto ao grupo oficial de Instrução Pública no ano de 1918, com a finalidade de erradicar o analfabetismo no país.

Lodi conclui essa seção revelando a morte de Lenin no ano de 1924 e de Krupskaia em 1939. É salientado ao leitor o pensamento revolucionário e contra-hegemônico da biografada, assim como, os diversos textos sobre educação que se tornaram uma referência em todo o bloco soviético.

No quarto capítulo, com o título de A Educação e a Revolução, Lodi a partir de um mapeamento que realizou em textos educacionais produzidos por Krupskaia, apresenta as contribuições da educadora no seu contexto histórico. Dentre os diversos escritos, a autora identifica: a) crítica em relação aos ensinamentos proporcionados a meninos e meninas, nos quais o sexo feminino era visto como aquele que deveria se dedicar as tarefas domésticas, enquanto ao sexo masculino, cabia o trabalho intelectual; b) defesa de uma solidariedade 


\section{Revista HIISTED : itilontine}

RESENHA

coletivista como única forma de acabar com individualismo e com as diferenças entre as classes, além de combater a competitividade que transformava as relações sociais em relações mercadológicas; c) proposição de uma educação que provesse desenvolvimento integral do ser humano e o posicionasse como sujeito ativo do processo educacional; d) a necessária formação do sujeito emancipado, que pense por si mesmo e que busque uma sociedade coletivista e solidária; e) a importância de considerar os aspectos da formação psicológica nas diferentes fases do desenvolvimento infantil; f) a necessidade de proporcionar às crianças estímulos visuais, auditivos, motores para o desenvolvimento da criatividade; g) defesa de uma escola unilateral, que envolva o corpo e o trabalho como elemento fundamental da realização do sujeito e que, ao mesmo tempo, esteja livre da influência do Estado e da religião.

Nas considerações finais, a autora traça um comparativo entre a visibilidade que é dada a mulher e a que é dada ao homem que atua em circunstâncias históricas importantes, em níveis de militância semelhantes. Nesse sentido, Lodi tece suas críticas quanto à desigualdade entre os sexos e segue em defesa de uma escola livre como a única forma de suprimir a construção social preconceituosa que situa a mulher em posição inferior ao homem. A partir disso, Lodi justifica a necessidade de dar visibilidade ao expoente feminino e sugere que outros pesquisadores busquem novas possibilidades de estudos, visto que há muito a ser explorado.

Nesse livro, pesquisadores e interessados no tema encontrarão uma fonte significativa de elementos para subsidiar o debate contemporâneo sobre as mais diversas questões que permeiam o campo das ciências humanas e sociais.

Por fim, trata-se uma obra consistente e profunda em suas análises, se constituindo uma referência fundamental para pesquisadores da área da educação e interessados em conhecer como a teoria marxista busca explicar a regulamentação das ações na educação e no ensino através dos modos de produção da vida material.

\section{AUTORIA:}

* Mestrado na Universidade Nove de Julho (UNINOVE). Professora da Secretaria Municipal da Educação de São Paulo. Contato: lusivisv@ hotmail.com

\section{COMO CITAR ABNT:}

VICENTE, L. da S. Uma estrela vermelha. Revista HISTEDBR On-line, Campinas, SP, v. 21, p. 1-4, abr. 2021. DOI: 10.20396/rho.v21i00.8657382. Disponível em: https://periodicos.sbu.unicamp.br/ojs/index.php/histedbr/article/view/8657382. Acesso em: 3 maio 2021. 